\title{
Study of fine needle aspiration cytology of palpable head and neck lesions in tertiary care centre
}

\author{
Jadhav D. $S^{1}$, Barge A. $K^{2, *}$, Valand A. $G^{3}$ \\ ${ }^{1}$ Associate Professor, ${ }^{2}$ Resident, ${ }^{3}$ Professor, Dept. of Pathology, Swami Ramanand Teerth Rural Government Medical College, \\ Ambajogai, Maharashtra, India
}

*Corresponding Author:

Email: barge.arti7@gmail.com

Received: $21^{\text {st }}$ January, 2018

Accepted: $14^{\text {th }}$ February, 2018

\begin{abstract}
Introduction: Fine Needle Aspiration Cytology (FNAC) of neck masses is a quick, easy, safe and cheap technique and has been a well accepted procedure in diagnosing various swellings. In head and neck regions FNAC is widely used such as in the lymph nodes, thyroid, salivary glands and other neoplasms.

Aims and Objectives: 1.To evaluates the role of FNAC and its utility in diagnosis of palpable head and neck masses; 2 . To study the spectrum of head and neck lesions in rural population; 3. To study diagnostic accuracy of FNAC by histopathological correlation wherever possible.

Materials and Methods: The present study includes 706 cases of palpable head and neck swelling in department of pathology of tertiary care centre from January 2016 to June 2017. Aspiration was done and cytological diagnosis was given. Cytohistopathological correlations were done wherever possible.

Result: Total 706 patients of palpable head and neck lesions studied out of that lymph node (33.00\%) was common site followed by, thyroid lesion (30.31\%), miscellaneous (22.80\%) and salivary gland (13.88). Most common nonneoplastic, benign neoplastic and malignant neoplastic lesion is reactive lymphadenitis, colloid goiter of thyroid and metastasis of squamous cell carcinoma in lymphnode respectively. Accuracy rate of FNAC in 70 cases which are correlated with histopathological examination was $95.71 \%$ with sensitivity and specificity of $78.57 \%$ and $100 \%$ respectively.

Conclusion: Fine needle aspiration cytology is simple, rapid and safe diagnostic tool with accuracy of $95.71 \%$ for differentiating neoplastic from nonneoplastic lesions of palpable head and neck region.
\end{abstract}

Keywords: FNAC, Head and neck, Lymphnode, Thyroid.

\section{Introduction}

Fine Needle Aspiration Cytology (FNAC) of neck masses is a quick, easy, safe and cheap technique in the diagnosis and has been a well accepted procedure in diagnosing various swellings. ${ }^{1}$ Fine Needle Aspiration Cytology (FNAC) is a simple and a rapid diagnostic technique and it is now being considered as a valuable diagnostic aid because of the early availability of results, simplicity, minimal trauma and absence of complications such as in the thyroid, lymph nodes, major salivary glands and other neoplasm's. FNAC is of great value in the head and neck regions because of the multiplicity of accessible organs and heterogeneous pathologies encountered. ${ }^{2}$ The close proximity of various types of tissues at this site and a wide range of primary and metastatic neoplasm's make it one of the most interesting and challenging in FNAC diagnosis. This technique is an outpatient department procedure and causes minimal trauma and no risk of complication. It can be performed under local anaesthesia, particularly useful if a neck lump is thought to be malignant. ${ }^{3}$ In head and neck swellings differential diagnosis include a broad spectrum of diseases with differing implications for management. FNAC provides for a suitable and useful method of assessment of these lesions. ${ }^{4}$

FNA is highly suitable for debilitated patients and repeatedly useful for multiple swellings with low risk of complications, speedy result and painless procedure. Fine needle aspiration is part of a clinical sequence in which the doctor examines the patient, performs the aspirate, reads the smear, discusses diagnosis with the colleagues and delivers the report or repeats smear. Most accurate results are achieved in this manner. This is standard practice in Scandinavia, selected centres in Europe and the United States. ${ }^{5}$ The present study is undertaken to study the accuracy and utility of FNAC in diagnosis of head and neck lesions in patients coming from rural areas to government tertiary care hospital in a period from January 2016 to June 2017.

\section{Materials and Methods}

The present study include outdoor and indoor cases of palpable head and neck swelling in department of pathology, government medical college in period of January 2016-June 2017. All age and sex were included with proper clinical history was taken. The patient was positioned to allow the most optimal digital palpation of the mass. Taking all aseptic measures, the mass was fixed with the left hand. A $5 \mathrm{cc}$ or $10 \mathrm{cc}$ plastic disposable syringe with an attached 22 to 26 gauge needle was placed inside the mass. Several rapid short strokes were made in different directions then needle was withdrawn after aspiration and haemostasis was achieved with gauze pad. Aspirated material from 
needle was smeared on clean glass slide with the help of another slide. In this way, two to four smears were prepared air dried smear stain with May Grunwald Giemsa and ethyl alcohol fixed smears were stained with Papanicolaou stain. Special stains used were ZiehlNeelsen (ZN) stain for acid fast bacilli. The stained slides were mounted by DPX and examined under the light microscope and reported.

\section{Result}

Fine needle aspiration cytology was done in total 706 cases of palpable head and neck swellings with incidence of $22.50 \%$ out of 3138 cases of all FNACs. Site wise distribution of head and neck FNAC [Table1] shows lymph nodes lesion (33\%) was the predominant site followed by thyroid lesions (30.31\%), miscellaneous $(22.80 \%)$ and salivary gland lesions $(13.88 \%)$. The youngest patient in the study was 2 year old and the oldest was 80 year of age with mean age of 37.95 years and 35 year median and peak incidence of age group was third decade. Male to female ratio was 1:1.42 with females were predominance. Head and neck lesions were cytologically categorised into nonneoplastic $(52.12 \%)$, neoplastic $(45.89 \%)$ and remaining $(1.98 \%)$ were inadequate due to scant cellularity and haemorrhagic aspirate [Table 2]. In non neoplastic lesion, reactive lymphadenitis was predominant lesion followed by epidermal cyst, granulomatous lymphadenitis and tuberculous lymphadenitis. Neoplastic lesions were further classified into benign and malignant lesion. In benign neoplastic lesion most commonly found lesion was colloid goiter of 152 cases followed by lipoma, pleomorphic adenoma of salivary gland. Cases of colloid goiter were more in overall FNAC of head and neck lesion in present study. In malignant neoplastic lesions, metastasis from squamous cell carcinoma in lymphnode was predominant lesion followed by papillary carcinoma of thyroid, mucoepidermoid carcinoma of salivary gland.

\section{Table 1: Site wise distribution of head and neck} masses

\begin{tabular}{|l|c|c|}
\hline \multicolumn{1}{|c|}{ Site } & No. of cases & Percentage\% \\
\hline Lymphnode & 233 & $33.00 \%$ \\
\hline Thyroid & 214 & $30.31 \%$ \\
\hline Salivary gland & 98 & $13.88 \%$ \\
\hline Miscellaneous & 161 & $22.80 \%$ \\
\hline Total & 706 & 100 \\
\hline
\end{tabular}

Table 2: Cytological category wise distribution of head and neck lesions

\begin{tabular}{|l|c|c|}
\hline $\begin{array}{c}\text { Cytological } \\
\text { category }\end{array}$ & No. of cases & Percentage\% \\
\hline $\begin{array}{l}\text { Non } \\
\text { neoplastic }\end{array}$ & 368 & 52.12 \\
\hline Neoplastic & 324 & 45.89 \\
\hline Inadequate & 14 & 1.98 \\
\hline Total & 706 & 100 \\
\hline
\end{tabular}

Lymphnode lesions were predominant in third decade and $\mathrm{M}$ : F ratio was $1.24: 1$. Out of $233(33.00 \%)$ cases of lymphnode lesions, most common lesion was reactive lymphadenitis $(32.62 \%)$ followed by granulomatous lymphadenitis $(24.03 \%)$. In malignant lesions, metastasis from squamous cell carcinoma was the predominant finding $(14.16 \%)$ followed by non Hodgkin's lymphoma $(0.86 \%)$, metastasis from adenocarcinoma $(0.43 \%)$. [Table 3]

Table 3: Distribution of cytological diagnosis of lymphnode swellings

\begin{tabular}{|l|c|c|}
\hline \multicolumn{1}{|c|}{ Cytological diagnosis } & No. of cases & Percentage \% \\
\hline Inflammatory & & \\
Nonspecific lymphadenitis & 31 & 13.30 \\
Reactive lymphadenitis & 76 & 32.62 \\
Tuberculous lymphadenitis & 33 & 14.16 \\
Granulomatous lymphadenitis & 56 & 24.03 \\
\hline Malignant & 2 & \\
Non Hodgkin's lymphoma & 33 & 0.86 \\
Secondary from squamous cell carcinoma & 1 & 14.16 \\
Secondary from adenocarcinoma & 1 & 0.43 \\
\hline Inadequate & 233 & 0.43 \\
\hline Total & & 100 \\
\hline
\end{tabular}

Thyroid gland lesions comprised of 214 (30.31\%) cases of all head neck lesions, observed in third decade with predominance in females with $\mathrm{M}$ : $\mathrm{F}$ ratio was1:6.92. Most common lesion was colloid goiter comprising of 152 cases $(71.03 \%)$ followed by Hashimotos thyroiditis $(14.02 \%)$, follicular neoplasm $(7.48 \%)$, thyroglossal cyst $(2.34 \%)$ and sub-acute thyroiditis $(0.93 \%)$. In malignant lesion papillary carcinoma $(1.87 \%)$ was more common followed by medullary carcinoma $(0.93 \%)$ of thyroid. Inadequate in 2 cases $(0.93 \%)$. In present study, colloid goiter was more common in head and neck lesion constituting 152 cases with female predominance and M:F ratio was 1:5.90 [Table 4]. 
Table 4: Distribution of cytological diagnosis of thyroid lesions

\begin{tabular}{|l|c|c|}
\hline \multicolumn{1}{|c|}{ Cytological diagnosis } & No. of cases & Percentage \% \\
\hline Inflammatory & & \\
Hashimotos thyroiditis & 30 & 14.02 \\
Subacute thyroiditis & 2 & 0.93 \\
Thyroglossal cyst & 5 & 2.34 \\
\hline Benign & 152 & 71.03 \\
Colloid goiter & 16 & 7.48 \\
Follicular neoplasm & 1 & 0.47 \\
Hurthle cell neoplasm & 4 & 1.87 \\
\hline Malignant & 2 & 0.93 \\
Papillary carcinoma & 2 & 0.93 \\
Medullary carcinoma & 214 & 100 \\
\hline Inadequate & & \\
\hline Total & & \\
\hline
\end{tabular}

Total $98(13.88 \%)$ cases of salivary gland lesions were observed in third decades having slight male predominance with male to female ratio of 1.17:1. Most common salivary gland lesion observed was sialadenitis $44(44.9 \%)$ cases, out of which $25(25.51 \%)$ cases of chronic sialadenitis and 19(19.39\%) cases of acute sialadenitis. Pleomorphic adenoma was common benign neoplasm comprising of $23(23.47 \%)$ cases of all salivary gland lesions with female predominance, followed by 2 cases of lymphoepithelial lesions consisting of $2(2.04 \%)$ cases. There were total 6 malignant salivary gland lesions; three diagnosed as mucoepidermoid carcinoma (3.06\%), one as acinic cell carcinoma (1.02\%), one as adenoid cystic carcinoma $(1.02 \%)$ and one as carcinoma ex pleomorphic adenoma $(1.02 \%)$ [Table 5].

Table 5: Distribution of cytological diagnosis of salivary gland lesions

\begin{tabular}{|l|c|c|}
\hline \multicolumn{1}{|c|}{ Cytological diagnosis } & No. of cases & Percentage \% \\
\hline Inflammatory & 44 & 44.90 \\
Sialadenitis & 16 & 16.33 \\
Simple cystic lesions & 23 & \\
\hline Benign & 2 & 23.47 \\
Pleomorphic adenoma & 3 & 2.04 \\
Lymphoepithelial lesions & 1 & 3.06 \\
\hline Malignant & 1 & 1.02 \\
Mucoepidermoid carcinoma & 1 & 1.02 \\
Acinic cell carcinoma & 7 & 1.02 \\
Adenoid cystic carcinoma & 98 & 7.14 \\
Carcinoma ex Pleomorphic adenoma & & 100 \\
\hline Inadequate & & \\
\hline Total & & \\
\hline
\end{tabular}

Miscellaneous lesions were accounted for 161 $(22.80 \%)$ cases, in which most common lesion was epidermal cyst consisting of $75(46.58 \%)$ cases. Common benign lesion was lipoma comprising of 74
(45.96\%) cases, followed by benign adnexal tumor of 6 $(3.73 \%)$ cases. In malignant miscellaneous lesion, there were two cases, one sarcoma and another case was of porocarcinoma. [Table 6]

Table 6: Distribution of cytological diagnosis of miscellaneous lesions

\begin{tabular}{|l|c|c|}
\hline \multicolumn{1}{|c|}{ Cytological diagnosis } & No. of cases & Percentage\% \\
\hline Epidermal cyst & 75 & 46.58 \\
\hline Benign & 74 & 45.58 \\
Lipoma & 6 & 3.73 \\
Benign adnexal tumor & 1 & \\
\hline Malignant & 1 & 0.62 \\
Sarcoma & 4 & 0.62 \\
Positive for epithelial malignancy & 161 & 2.48 \\
\hline Inadequate & & 100 \\
\hline Total & \\
\hline
\end{tabular}


Cytohistopathological correlation was available in 70 cases. Histopathological examination was done in 4 cases of reactive lymphadenitis which confirmed the diagnosis in two cases. The other two cases were diagnosed as Hodgkin's lymphoma and non Hodgkin's lymphoma. The histopathological examination was done in 6 cases of follicular neoplasm which confirmed the diagnosis in 5 cases and another one diagnose as a follicular carcinoma. Histopathological examination was consistent in remaining 67 cases. Thus there were total 11 true positive, 56 true negative and 1 false negative cases with zero false positivity in present study. The diagnostic accuracy, sensitivity and specificity of FNAC in present study were $95.71 \%$, $78.57 \%$ and $100 \%$ respectively.

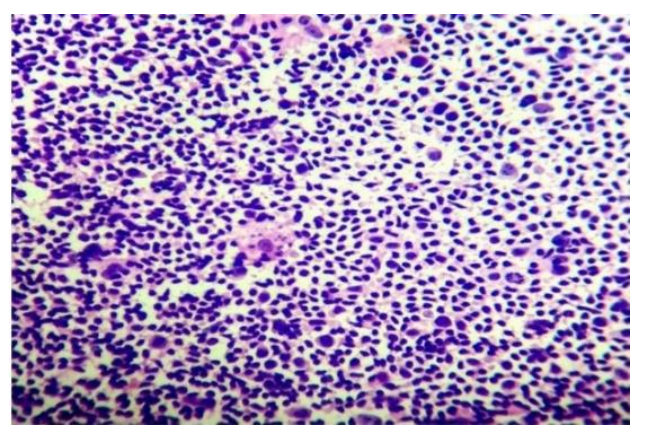

Fig. 1: Reactive lymphadenitis (Pap, 40X) smear shows mixed population of lymphoid cells, containing centroblasts, centrocytes, small lymphocytes and tangible body macrophages

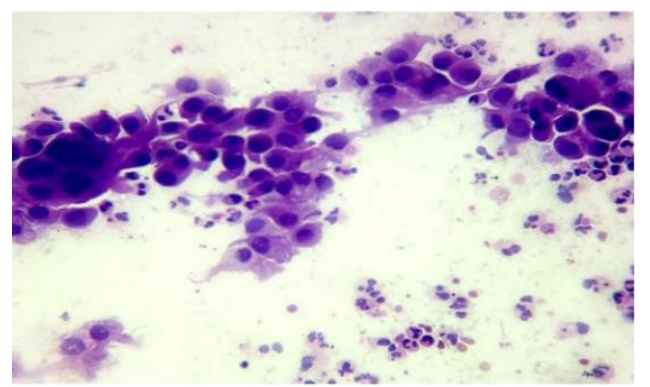

Fig. 2: Metastasis from squamous cell carcinoma (Pap 40X), Smear shows small and large sheets of squamous cell with hyperchromatic nuclei with increased $\mathrm{N}$ : $\mathrm{C}$ ratio and having moderate cytoplasm. Background shows inflammatory cells

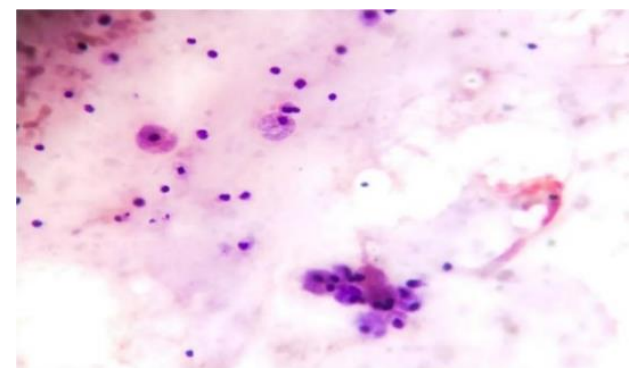

Fig. 3: Colloid goiter (Pap, 40X), photomicrograph shows colloidophages in colloid background

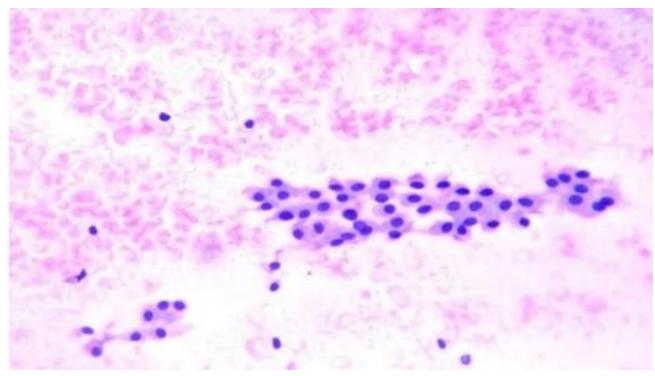

Fig. 4: Hurthle cell neoplasm (Pap, 40X): Photomicrograph shows clusters and singly scattered follicular cells with abundant granular eosinophilic cytoplasm

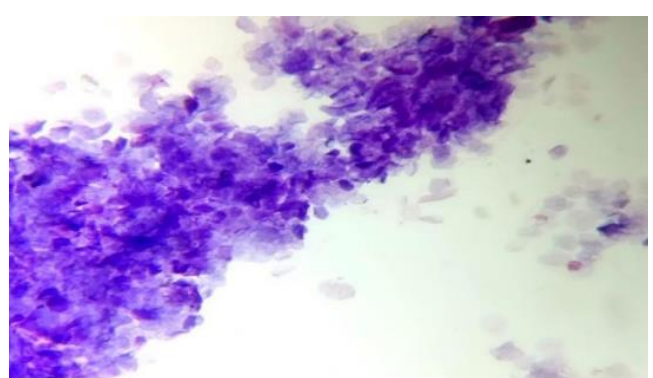

Fig. 5: Epidermal cyst: photomicrograph showing numerous nucleated as well as anucleated squamous cells

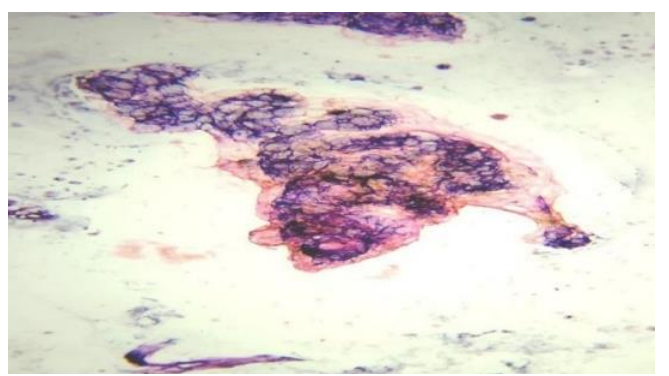

Fig. 6: Lipoma (Pap, 10X) Smear show clusters of mature adipocytes with eccentric nucleus.

Background shows haemorrhage

\section{Discussion}

Fine needle aspiration cytology of palpable head and neck lesions include many inflammatory, cystic lesion and neoplasms. FNAC is a first diagnostic step in identifying nature of pathogenesis. FNAC has safe, accurate and superior modality in diagnosis of various lesions. Many studies have been carried out to establish the role of FNAC in the evaluation of swelling in head and neck region. The present study comprises fine needle aspiration cytology of palpable masses in the head and neck region in rural area from January 2016 to June 2017. The cytological study helps us to categorize whether a particular lesion is benign or malignant. Most of the patients coming to our hospital belong to rural areas and they have low socioeconomic status and low education level. Many of them regularly chew tobacco and smoke and are generally ignorant about their health. So, infectious diseases and malignant conditions 
constitute a significant proportion of health problems in patients of rural area.

In study, lymphnode lesions were most common, followed by thyroid, miscellaneous lesions and salivary gland lesions. Similar observations were also noted by other studies such as Lalji Valiya et $\mathrm{al}^{6}$, Deval N Patel et $\mathrm{al}^{7}{ }^{7}$ Yogesh Pawade et $\mathrm{al}^{8}$ and Bhagat VM et al. ${ }^{9}$ Study includes total 706 cases of age $2 \mathrm{yr}$ to $80 \mathrm{yrs}$. Total mean age was $37.95 \mathrm{yr}$, median was $35 \mathrm{yr}$. Peak incidence of age group was 21-30 yrs. Similar observation of peak incidence of age group was also noted by Gogoi Geetanjali, ${ }^{10}$ Singal $\mathrm{P}$ et $\mathrm{al}^{11}$ study. Male: female ratio was $1: 1.42$ with female preponderance. This result was also reported by other studies such as Kishor $\mathrm{H}$ et al, Muddegowda et al, ${ }^{12}$ Valiya $\mathrm{L}$ et $\mathrm{al}^{6}$ and Shaan et al. ${ }^{13}$

Lymphnode: In our study, most common lymphnode lesion was reactive lymphadenitis $(32.62 \%)$. Similar results were also made by other studies, such as Pradeep Tendon et al,,${ }^{14}$ Gogoi Geetanjali, ${ }^{10}$ Sreedevi $\mathrm{P}$ et $\mathrm{al}^{15}$ studies. Maximum number of patients in second decade followed by first decade. There were total 76 cases of reactive lymph nodes and histopathological examination was done in four cases which confirm reactive lymphadenitis in two cases and in other two cases diagnosis was different. Out of these cases one diagnose as Hodgkin's lymphoma and other as Non Hodgkin's lymphoma. Diagnosis of lymphoma might have been missed mostly due to aspiration from non representative area or inability of needle to reach the exact site of lesion. Shaan et al had also similar example where two cases of reactive lymphnode misdiagnose as Hodgkin's and non Hodgkin's lymphoma reported reason for misdiagnosis was presence of atypical mononuclear cells, background infiltrated with eosinophils and hypocellularity of aspirate disproportionate to lymphnode size which must alerts the cytopathologist to the possibility of Hodgkin's lymphoma. Tilak et $\mathrm{a}^{16}$ state that Hodgkin's lymphoma may start at one place in the lymph node and the needle may not hit that particular area. Sometimes one or two lymph nodes in a group may be involved by Hodgkin's lymphoma. But sampling may occur through non involved lymph nodes resulting in misdiagnosis of reactive lymphadenopathy. Granulomatous lymphadenitis was second common cause of lymphnode lesion on cytology it shows granuloma with absence of acid fast bacilli. Tuberculous lymphadenitis lesions were $14.16 \%$ of all lymphnode cases. For diagnosis of tuberculosis on FNAC various authors used different criteria. Tilak et al diagnose tubercular lymphadenitis irrespective AFB positivity which shows degenerating and viable polymorphs, degenerating granuloma and caseous necrotic background with frankly purulent aspirate. According to Das et al, when AFB is positive in a smear containing epitheloid cell granuloma and / or necrosis, it is diagnostic of tuberculous lesion. When AFB is negative in the presence of epitheloid granuloma in a developing country like India, it is considered as a Granulomatous lesion likely to be of tuberculous etiology. In present study metastatic deposits accounts $14.59 \%$ of all lymphnode cases and it was the most common cause of malignancy in lymphnode. Similar findings were also noted by other studies such as Tandon et al, ${ }^{14}$ Hirachand et al studies where metastatic lymphadenopathy accounted 10.34\%, $12.3 \%$ respectively. Histopathological examination was done in two cases of metastatic lymphnode which confirmed the diagnosis of metastasis from squamous cell carcinoma and it is common cause leading to metastasis. These finding correlates well with the studies done by others. Metastatic adenocarcinoma was the second most common metastatic malignant lymphnode lesions comprising one case. There were two cases of non Hodgkin's lymphoma accounting 0.86 $\%$.

Thyroid Lesions: Thyroid lesions constitute second most common site in head and neck lesion accounting for $30.31 \%$ (214 cases). Maximum number of cases were females with predominant of third decade. In our study, out 214 cases of thyroid lesions 27 were males and 187 were females. Thyroid lesions occurred predominately in females with $\mathrm{M}$ : F ratio 1: 6.93 . Similar observations of female predominance were made by Afroz $\mathrm{N}$ et al ${ }^{17}$ and Jain $\mathrm{D}^{18}$ et al. In present study, most of the thyroid lesions were benign which were comparable with other studies such as Kishor $\mathrm{H}$ et $\mathrm{al},{ }^{19} \mathrm{M}$ Kate et $\mathrm{al}^{20}$ and $\mathrm{R}$ Goswami et $\mathrm{al}^{21}$ studies. Total $71.03 \%$ of thyroid lesions were consisting of colloid goiter which includes 13 cases of multinodular goiter and remaining 139 cases were colloid goiter. In present study most of the lesion in thyroid was colloid goiter followed by inflammatory lesions constituting Hashimoto's thyroiditis (14.02\%) and sub-acute thyroiditis $(0.93 \%)$ cases, followed by follicular neoplasm. In malignant lesion more number of cases was papillary carcinoma thyroid followed by medullary carcinoma of thyroid. Histopathological examinations were consistent in 38 cases out of 39 cases of thyroid lesions except in a case of follicular neoplasm which revealed follicular carcinoma, which was known cause of negativity. It requires histopathological examination to differentiate between adenoma and carcinoma. Colloid goiter was most common benign neoplasm in present study; females were affected more commonly than males with M: F ratio was 1:5.90. Colloid goiter was more commonly seen in fourth decade.

Salivary Gland: Salivary gland lesion accounted for $33.88 \%$ of 706 cases of all head and neck masses. More number of cases was sialadenitis constituting $44.90 \%$ of all salivary gland lesions. Out of $44.90 \%$ of sialadenitis chronic sialadenitis constitutes $25.51 \%$ and acute sialadenitis constitutes $19.39 \%$ of all salivary gland lesions, followed by pleomorphic adenoma in neoplastic lesions. Similar observations are made by 
Kishor $\mathrm{H}$ et a ${ }^{19}$ study. Common neoplastic lesion was Pleomorphic adenoma in salivary gland neoplasm. These findings are similar to Solanki $\mathrm{P}$ et al, ${ }^{22} \mathrm{M}$ Kate et $\mathrm{al}^{20}{ }^{20}$ Bhagat $\mathrm{VM}$ et $\mathrm{al}^{9}$ studies. There were total $23(23.47 \%)$ cases of pleomorphic adenoma predominantly found in 60-70 age group affecting females.

Miscellaneous Lesions: Miscellaneous lesions constitute $22.80 \%$ of all palpable head and neck lesions. These lesions were found more common in older age males. Epidermal cyst was the common finding accounting for $46.58 \%$ which was comparable with Valiya L et al, ${ }^{6}$ and Kishor $\mathrm{H}$ et al ${ }^{19}$ studies.

There were total 70 cases in which histopathological examination was done, out of those total 59 cases were benign which include inflammatory lesion, cystic lesion and benign neoplastic lesions and 11 cases were malignant neoplasm. Out of 59 benign lesions histopathological diagnosis was confirmed in $\mathbf{5 6}$ cases and false negative result in three cases. First cases turned as Hodgkin's lymphoma and second turned as Non Hodgkin's lymphoma in reactive lymphadenitis. There is mixed population of plasma cells and lymphoid cells in aspirate from non representative site of lesion was the cause of misinterpretation. Third case is of follicular neoplasm, this is the known limitation of FNAC in thyroid lesions. Distinction between adenoma and carcinoma requires histopathological examination for capsular or vascular invasion. There were 11 malignant cases and reveals $100 \%$ accuracy in histopathological diagnosis. All 11 cases were true positive, there are no false positive case. Accuracy of present study was $95.71 \%$, which was similar to other studies such as Fernandes $\mathrm{H}$ et $\mathrm{al}^{23}$ and Kishor $\mathrm{H}$ et al ${ }^{19}$ studies. Difference in sensitivity is due to more negativity. False negativity counteracted by taking multiple aspirations from representative area with adequate cellularity. In present study sensitivity was $78.57 \%$ and specificity was $100 \%$ and diagnostic accuracy was $95.71 \%$ which is comparable to values obtained in other studies.

\section{Conclusion}

In our study most common nonneoplastic, benign neoplastic and malignant neoplastic lesion are reactive lymphadenitis, colloid goiter of thyroid and metastasis of squamous cell carcinoma in lymphnode. Histopathological correlation was available in 70 cases with diagnostic accuracy, sensitivity and specificity was $95.71 \%, 78.57 \%$ and $100 \%$ respectively. Study has made, it clear that FNAC is the best investigation one can ask for with fairly good accuracy. Hence we conclude that fine needle aspiration cytology is simple, rapid, safe diagnostic tool with accuracy of $95.71 \%$ for differentiating nonneoplastic from neoplastic lesions of palpable head and neck region.

\section{References}

1. Devkota H, Sibakoti YC, Menyangbo S, Basnet S, Jha MK BL. Correlation of fine needle aspiration cytology and histopathology of the neck swellings presenting at national academy of medical sciences, kathmandu, nepal. Birat J Heal Sci. 2017;2(3):206-10.

2. Nallagutta N, Reddy SE, Gour S, Ayesha S, G J, Kotikalapudi R. Fine Needle Aspiration Cytology of Head and Neck Masses. Sch J App Med Sci. 2016;4(11B):3990-2.

3. Shekhar H, Kaur A, Agrawal P, Pancharia A, Jadeja P. Fine needle aspiration cytology in head and neck swellings: a diagnostic and therapeutic procedure. Int $J$ Res Med Sci. 2014;2(4):1667.

4. Afnan G, Vani BR, V SM. Fine Needle Aspiration Cytology Profile of Head and Neck Lesions in a Tertiary Care Hospital. Indian J Pathol. 2017;6(2):372-7.

5. Lever J V, Trott PA, A AJW. Review article Fine needle aspiration cytology. J Clin Pathol. 1985;38:1-11.

6. Valiya LG, Padhariya BB, Baxi SN. Spectrum of FNAC in Palpable Head and Neck Lesions in a Tertiary Care Hospital in Western India- A 2 Years Study. IOSR J Dent Med Sci. 2016;15(6):14-9.

7. Deval N. Patel, Parth B. Patel, Himani V. Patel TJ, Gandhi. Fine needle aspiration cytology role in head and neck lesions. Int Arch Inte grated Med. 2015;2(8):99-104.

8. Pawde Y, Kathale S. Fine Needle Aspiration Cytology As a Diagnostic Tool in Head and Neck Lesions. J Evol Med Dent Sci J Evol Med Dent Sci. 2014;3(45):11072-9.

9. Bhagat VM, Tailor HJ, Saini PK, Dudhat RB, Makawana GR, Ravi M. Fine Needle Aspiration Cytology in NonThyroidal Head and Neck Masses-a Descriptive Study in Tertiary Care Hospital. Natl J Med Res. 2013;3(3):273-6.

10. Gogoi G, Borgohain D. Fnac on Palpable Neck Masses A Hospital Based Study. Indian J Apllied Res. 2016;6(4):39-42.

11. Singal P, Ms B, Kharbanda J, Ps S. Efficacy of fine needle aspiration cytology in Head and Neck lesions. IJMDS. 2014;3(2):421-30.

12. Muddegowda P, Srinivasan S, Lingegowda J, KR R, Murthy K. Spectrum of Cytology of Neck Lesions: Comparative Study from Two Centers. J Clin Diagnostic Res. 2014;8(3):44-5.

13. Khetrapal S, Jetley S, Jairajpuri Z, Rana S, Kohli S, Safia R. Fnac of head \& neck lesions and its utility in clinical diagnosis: a study of 290 cases. Natl j med res. 2015;5(1):33-8.

14. Tandon P, Gautam W. Utility of Fine Needle Aspiration Cytology in Lymphadenopathy - A Study of 638 Cases in a Primary Care Setting. Natl J Lab Med. 2016;5(3):11-5.

15. P Sridevi, Ch Kishor kumar, C PN. Diagnostic Role of FNAC in Evaluation of Head and Neck Lesions. IOSR J Dent Med Sci. 2016;15(9):11-3.

16. Tilak V, Dhaded A., Jain R. Fine needle aspiration cytology of head and neck masses. Indian J Pathol Microbiol. 2002;45(1):23-30.

17. Afroze N, Kalyania N, Hasan sheema H. Role of fine needle aspiration cytology in the diagnosis of palapable thyroid lesions. Indian $j$ patho.microbiol. 2002;45(3):241-6.

18. Jain D, Jain N. Evaluation of Thyroid Swelling By Fine Needle Aspiration Cytology: A Single Institute Experience in Uttrakhand Region of Northern India. IOSR J Dent Med Sci. 2017;16(5):32-4.

19. Suryawansh KH, Damle R, Dravid N et al. Spectrum of FNAC in palpable head and neck lesions in a tertiary care hospital in India-a 3 years study. Indian J Pathol Oncol. 2015;2(1):7-13. 
20. Kate Minakshi SS. Spectrum of lesions in head and neck region on fine needle aspiration cytology. Southeast Asian J Case Rep Rev. 2015;4(6):2092-101.

21. Goswami RR, Baruah D, Devi G. Fnac Spectrum of Head and Neck Lesions - a Retrospective Study. J Evid Based Med Healthc. 2016;3(13):400-5.

22. Solanki PK, Patel AP, Taviad PP, Chaudhari VP, Patel S $\mathrm{m}$. Fine needle aspiration cytology as a diagnostic procedure in head and neck swellings. Natl $j$ Community Med. 2012;3(3):433-6.

23. Fernandes H, D'Souza CRS, Thejaswini BN. Role of fine needle aspiration cytology in palpable head and neck masses. J Clin Diagnostic Res. 2009;3(5):1719-25.

How to cite this article: Jadhav DS, Barge $\mathrm{AK}^{*}$, Valand AG. Study of fine needle aspiration cytology of palpable head and neck lesions in tertiary care centre. Ind J Pathol Oncol, 2018;5(3):375-381. 